of lymph node metastases, which may have affected results. Certainly these results have not been demonstrated by other investigators that have found no statistically significant difference between squamous differentiation and pure TCC, although many have shown mortality reductions with other subtypes such as adenocarinoma, carcinosarcoma and small cell carcinoma of the bladder (1-3). Nonetheless, it remains crucial that further, preferably randomized or well conducted retrospective studies are performed, to confirm which TCC subtypes truly portend a poorer prognosis. This data could then be used to assist in the integration of chemotherapy or radiotherapy, together with surgery in the management of these aggressive cancers in order to improve clinical outcomes.

\section{References}

1. Richie JP, Waisman J, Skinner DG, Dretler SP: Squamous carcinoma of the bladder: treatment by radical cystectomy. J Urol. 1976; 115: 670-2.

2. Ghoneim MA, el-Mekresh MM, el-Baz MA, el-Attar IA, Ashamallah A: Radical cystectomy for carcinoma of the bladder ; critical evaluation of results in 1026 cases J Urol. 1997; 158: 393-9.

3. Rogers CG, Palapattu GS, Shariat SF, Karakiewic PI, Bastian PJ, Lotan Y, et al.: Clinical outcomes following radical cystectomy for primary non transitional cell carcinoma of the bladder compared to transitional cell carcinoma of the bladder J Urol. 2006; 175: 2048-53.

Dr. Mark Frydenberg

Department of Urology

Monash Medical Centre, Monash University

Victoria, Australia

E-mail: frydenberg@optusnet.com.au

\title{
Re: The Role of Squamous Differentiation in Patients with Transitional Cell Carcinoma of the Bladder Treated with Radical Cystectomy
}

\author{
Alberto A. Antunes, Luciano J. Nesrallah, Marcos F. Dall'Oglio, Carlos E. Maluf, Cesar Camara, \\ Katia R. Leite, Miguel Srougi \\ Division of Urology, University of Sao Paulo Medical School, Sao Paulo, Brazil and Hospital Sirio \\ Libanes, Sao Paulo, Brazil
}

Int Braz J Urol, 33: 339-346, 2007

To the Editor:

Squamous differentiation is well known to occur in the bladder urothelial carcinoma and represents the most common form of mixed differentiation (1-5). When defined by the presence of intercel- lular bridges and/or keratinization in urothelial carcinoma, it occurs in $21 \%$ of urothelial carcinomas of the bladder, and in $44 \%$ of tumors of the renal pelvis (2-3). Its frequency increases with grade and stage 
(2-3). The diagnosis of squamous cell carcinoma is reserved for pure lesions without any associated urothelial component, including urothelial carcinoma in situ (5). Tumors with any identifiable urothelial element are classified as urothelial carcinoma with squamous differentiation and an estimate of the percentage of squamous component should be provided (3-5).

The clinical significance of squamous differentiation remains uncertain, but seems to be an unfavorable prognostic feature in such patients undergoing radical cystectomy, possibly, because of its association with high-grade tumors (1-5). This is supported by Antunes et al. (1). These authors have conducted an interesting study related to clinical implications of squamous differentiation in urothelial carcinoma treated by radical surgery. In their study, $22 \%$ of tumors had squamous differentiation, but most importantly, they observed a higher disease recurrence and mortality in patients having squamous differentiation as compared with patients without squamous differentiation. Antunes et al. (1), also found squamous differentiation as independent predictor of survival in patients with bladder cancer after radical surgery. This study provides nicely performed evidence on the usefulness of reporting the presence of squamous differentiation in urothelial carcinoma. Other studies have emphasized squamous differentiation as predictor of a poor response to radiation therapy, and possibly also to systemic chemotherapy, although the controversy still exists on this issues. To avoid some problems related to the criteria in assessing squamous differentiation, the use of immunohistochemical technique in addition to appropriated conventional analyses is advised (2). Cytokeratin 14, caveolin, uroplakins and L1 antigen have been reported as immunohistochemical markers of squamous differentiation since they are expressed in urothelial carcinoma and not in squamous differentiation (2). Finally, the main limitation of the study by Antunes et al. (1) is the small number of cases entering the analysis; therefore studies on the issue including larger series might be necessary to confirm the data by Antunes et al.

\section{References}

1. Antunes AA, Nesrallah LJ, Dall'Oglio MF, Maluf CE, Camara C, Leite KR, Srougi M: The role of squamous differentiation in patients with transitional cell carcinoma of the bladder treated with radical cystectomy. Int Braz J Urol. 2007; 33: 339-46.

2. Lopez-Beltran A, Cheng L: Histologic variants of urothelial carcinoma: differential diagnosis and clinical implications. Hum Pathol. 2006; 37: 1371-88.

3. Lopez-Beltran A, Requena MJ, Alvarez-Kindelan J, Quintero A, Blanca A, Montironi R: Squamous differentiation in primary urothelial carcinoma of the urinary tract as seen by MAC387 immunohistochemistry. J Clin Pathol. 2007; 60: 332-4.

4. Emerson RE, Cheng L: Immunohistochemical markers in the evaluation of tumors of the urinary bladder: a review. Anal Quant Cytol Histol. 2005; 27: 301-16.

5. Lopez-Beltran A, Sauter G, Gasser T: Urothelial Tumors: Infiltrating Urothelial carcinoma. In: Eble JN SG, Epstein JI, Sesterhenn I (eds). World Health Organization Classification of Tumors. Pathology and Gentics of Tumors of the Urinary System and Male Genital Organs. Lyon, IARC Press. 2004.

Dr. Maria J. Requena Dr.Antonio Lopez Beltran Urology Unit (MJR) Anatomic Pathology Unit (ALB) Department of Surgery Cordoba University Medical School Cordoba, Spain E-mail:em1lobea@uco.es 